УДК 005.591.1:658.26

\title{
АНАЛИЗ МЕТОДОВ УПРАВЛЕНИЯ КАЧЕСТВОМ ЭНЕРГОСБЕРЕГАЮЩИХ ПРОЦЕССОВ ПРОМЫШЛЕННОГО ПРЕДПРИЯТИЯ ${ }^{1}$
}

\author{
(C) 2012 г. О. Н. Лагутина
}

\section{ЗАО «Ростовгазоапnарат», г. Ростов-на-Дону}

Проанализирована методологическая база управления качеством в энергосбережении. Рассмотрены международные стандарты систем энергетического менеджмента. Предложень подходы к модификаиии ичикла совершенствования энергосберегающей политики предприятия.

Ключевые слова: управление; энергосбережение, управление качеством; программноиелевой метод.

In the article author analyzed the methodological basis of the quality control methods for energy saving. The international standards of energy management systems are also examined. Some ways of modifying the enterprise's energy saving policy are presented.

Key words: management; energy saving; quality management; management by objectives.

Промышленный спрос на энергоресурсы изменяется в зависимости от регионов и стран, от уровня развития экономики, от степени технологического развития и ряда других факторов.

Энергия используется в промышленности для широкого круга мероприятий, таких как обработка и сборка, освещение и другие.

Промышленный сектор, в совокупности, потребляет больше энергии, чем любой другой сектор, потребляя примерно половину от общего числа получаемой энергии в мире.

Сокращение использования энергоресурсов приходится на 2009 год, что вызвано глобальным экономическим кризисом, который начался в 2008 году и углубился в 2009 году (рис. 1) [8].

В долгосрочной перспективе мировые темпы экономического роста могут вернуться к исторической тенденции (рис. 2) [8].

Большая часть долгосрочного роста спроса в промышленном секторе на энергоресурсы происходит в странах, не входящих в Организацию Экономического Сотрудничества и Развития (ОЭСР).

В настоящее время странами, не являющимися членами ОЭСР, потребляется $62 \%$ мировой энергии, потребляемой в промышленном секторе. С 2008 по 2035 гг. промышленное потребление энергии в странах, не входящих в ОЭСР, будет расти в среднем на $2 \%$ в год, в то время как в странах ОЭСР - на $0,5 \%$ в год (рис. 3) [8].

Таким образом, 89\% роста использования в промышленном секторе использования энергии, $71 \%$ от общего числа используемой энергии в 2035 году в промышленном секторе будет приходиться на страны, не входящие в ОЭСР [8].

На пять отраслей промышленности приходится $60 \%$ всей энергии, используемой в промышленном секторе (рис. 4): химикаты $(33 \%)$, железо и стали (14\%), неметаллические полезные ископаемые (7\%), целлюлозно-бумажная $(4 \%)$, и цветные металлы $(3 \%)$ [8].

1 Результаты работы получены при поддержке Минобрнауки РФ в рамках государственного задания на проведение НИОКР, шифр заявки 6.2989.2011. 




п промышленный сектор

другие секторы

Рис. 1. Ежегодные изменения в потреблении энергии мировой промышленностью и во всех других секторах конечного использования энергии

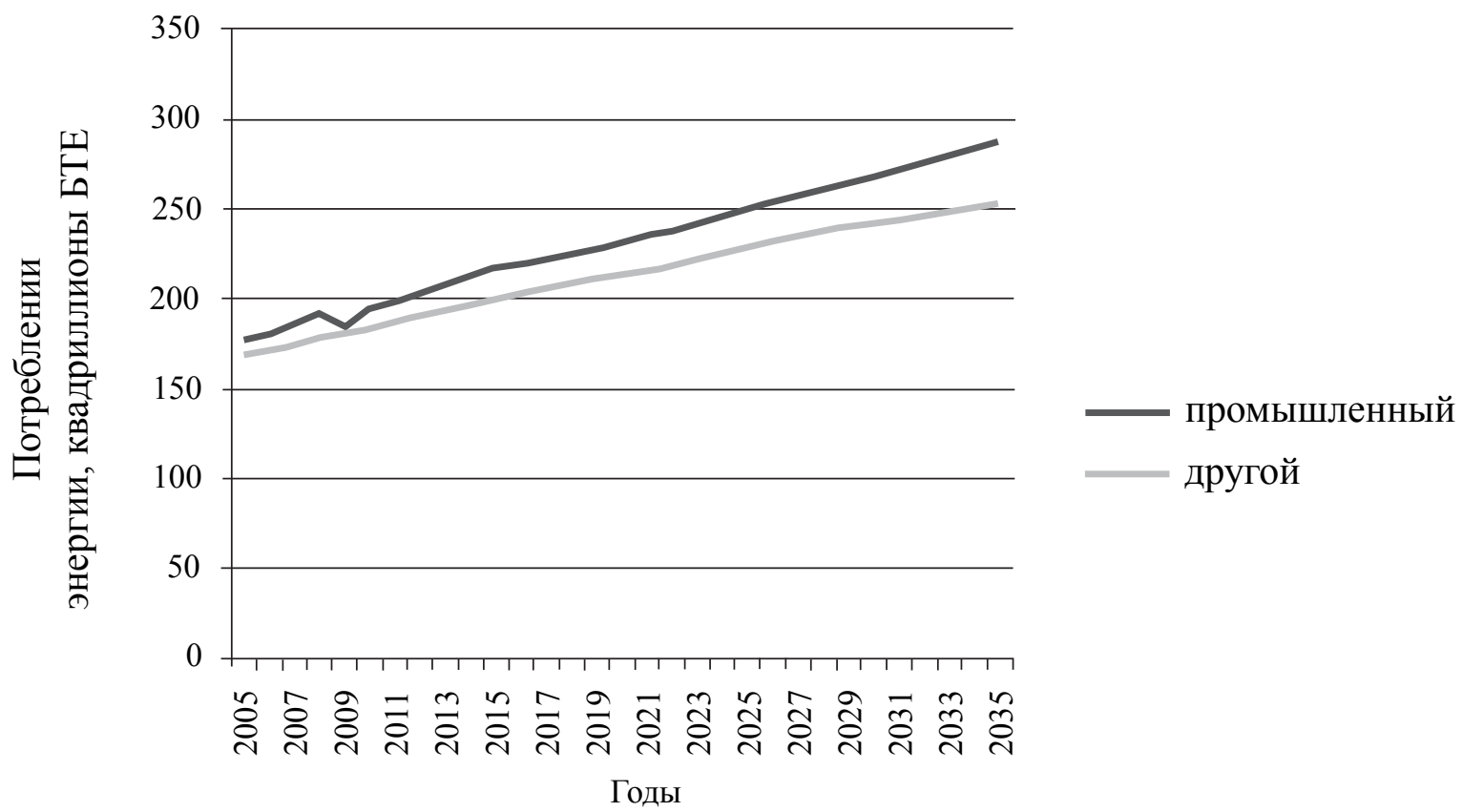

Рис. 2. Мировое потребление в промышленности и в других секторах конечного использования, 2005-2035 гг. 


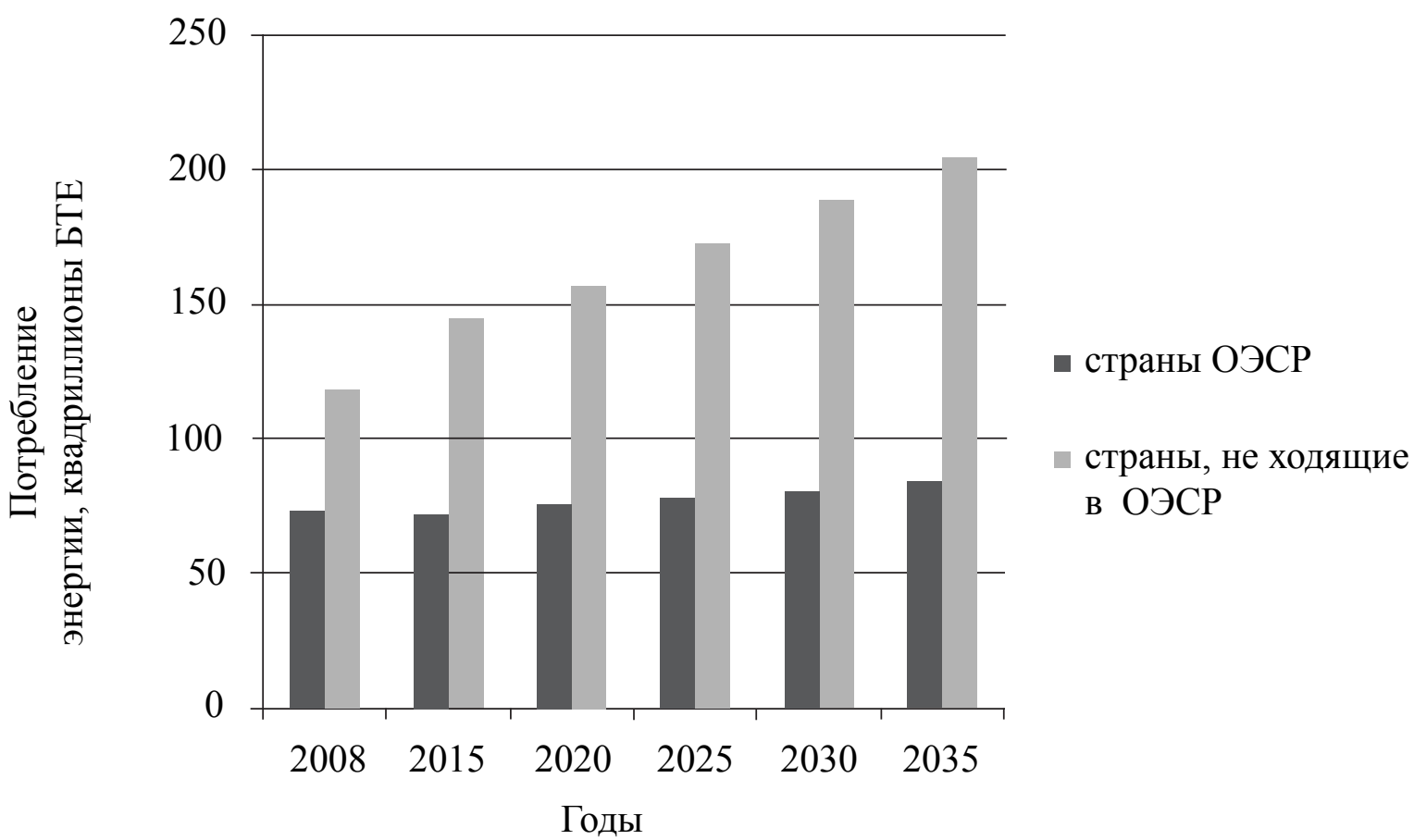

Рис. 3. Потребление энергии в промышленности стран, входящих и не входящих в ОЭСР, 2008-2035 гг.

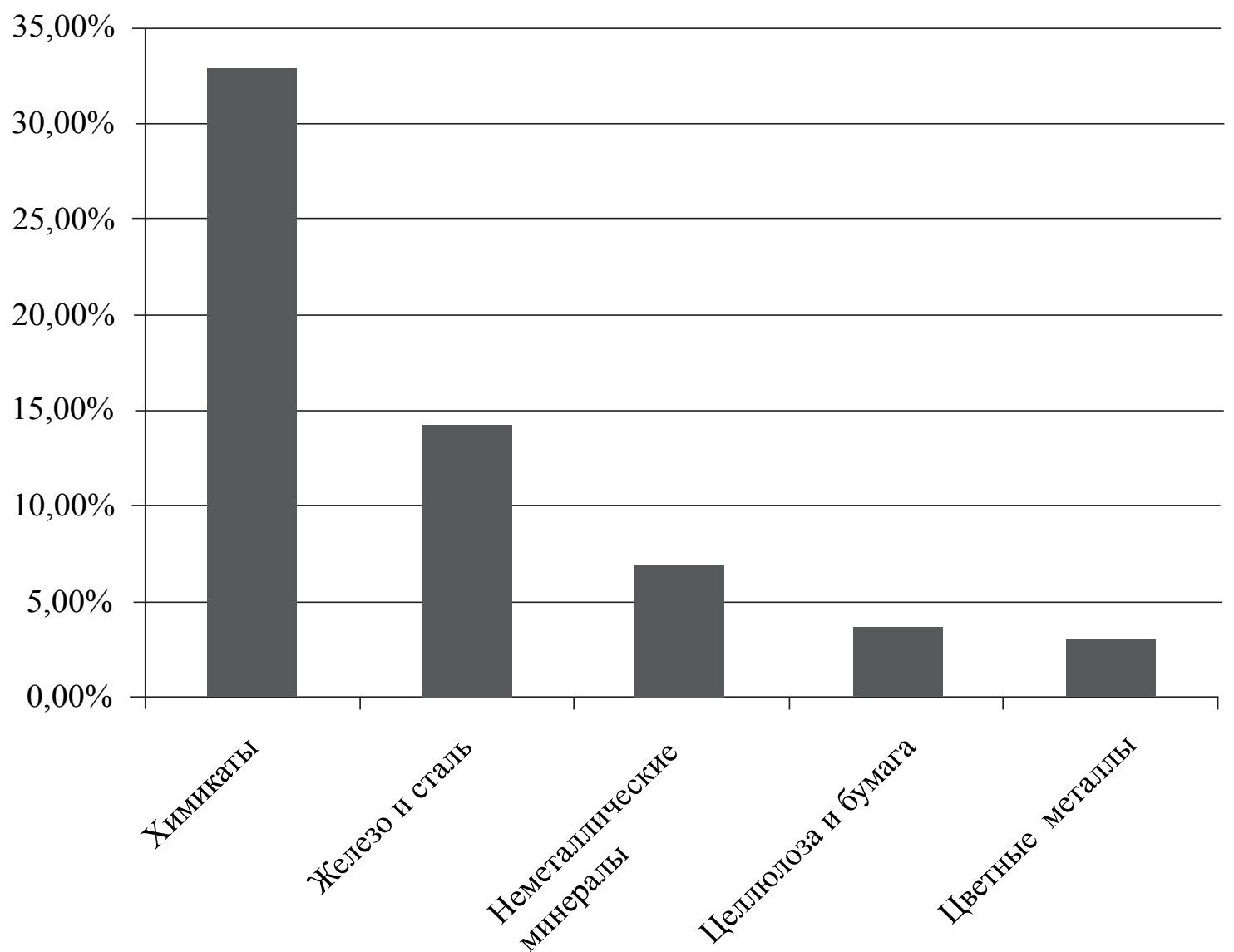

Рис. 4. Потребление энергии в промышленном секторе по основным энергоемким отраслям, 2008 г. 
Следовательно, величина и структура топливного баланса будущего промышленного потребления энергии будет, в значительной степени, определятся использованием энергии в этих пяти отраслях промышленности.

Если объединить мировые тенденции использования энергоресурсов (табл. 1), то мы увидим, что тенденция в странах ОЭСР и в странах, не являющихся членами ОЭСР, идет к увеличению использования энергоресурсов. Правда, в странах ОЭСР среднегодовые темпы роста меньше на $2 \%$.

В России, промышленное потребление энергии формируется в значительной степени от роли страны как крупного производителя энергии. Развитие промышленности России в настоящее время значительно отстает за счет высокой доли энергетических затрат в количестве общих затрат производства. Особенно высоки энергетические затраты в сфере машиностроения, где они также имеют тенденции к росту за счет значительного морального и физического износа оборудования на предприятиях и больших затратах при перевозке энергетических ресурсов. По прогнозным данным экономика России будет расти в среднем на 2,6 процента в год с 2008 по 2035, с учетом промышленного спроса на энергию примерно в $35 \%$ от общего потребления энергии в течение всего периода. Энергоемкости ВВП России является самой высокой в мире, и хотя в некоторых случаях энергоемкость снижается, Россия останется одной из наименее энергоэффективных экономик мира до 2035 года.На долю природного газа (самого богатого отечественного природного источника энергии) в России приходится почти половина от общего числа промышленного использования энергии. Доля электроэнергии в промышленности будет увеличиваться до 2035 года.
Применение программно-целевого метода к формированию программ энергосбережения на промышленных предприятиях

Современная ситуация на российском рынке требует решения задач снижения ресурсов за счет различных мер в том числе, научно-технических, экономических, организационных. Немаловажным является тот факт, что не только обеспечение развития, но и сохранение энергетической политики предприятия на должном уровне является довольно сложной задачей. Отсюда следует сделать вывод, что одним из приоритетных направлений является улучшение методологии управления процессом энергосбережения. Следует отметить, что предотвращение больших финансовых потерь при формировании совокупности энергосберегающих мероприятий позволит уменьшить энергетическую составляющую затрат производства и высвобожденные средства направить на улучшение уровня морального и физического износа оборудования, используемого в производственном процессе.

Главным фактором в энергосберегающей политике предприятий является рациональное использование энергетических ресурсов и четкий контроль на всех этапах энергосберегающей политики предприятия, для чего необходимо создавать определенную методологическую базу управления этими процессами [5].

Методологическая база в области управления энергосбережением очень обширна. Все методы управления энергосбережением можно представить в виде следующей схемы (рис. 5). Независимо от характера этих методов их цели сводятся к сугубо коммерческим и социальным целям общества в целом, Последние могут быть сформулированы на ос-

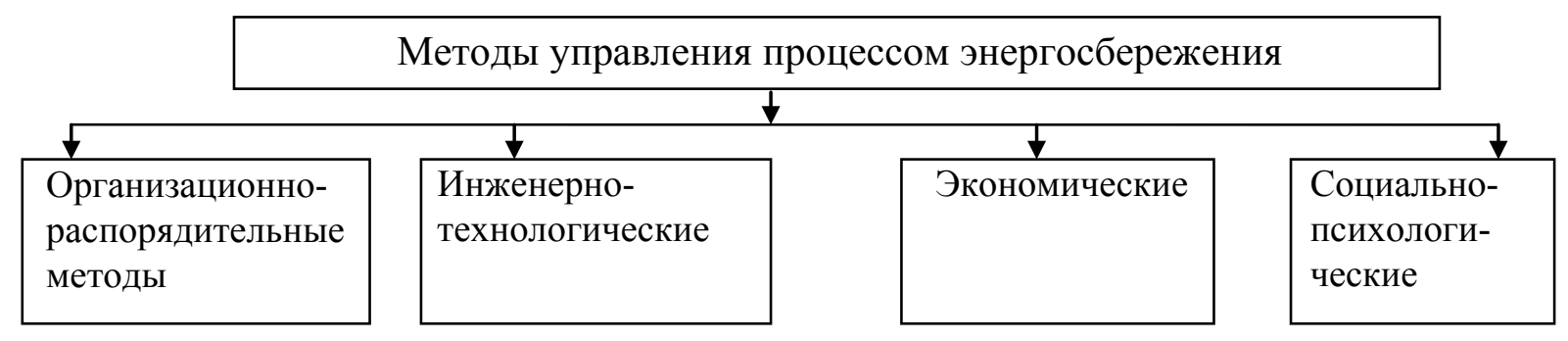

Рис. 5. Методы управления процессом энергосбережения 
Таблица 1

Мировая тенденция в промышленности по использованию видов энергии во временном интервале [8]

\begin{tabular}{|c|c|c|c|c|c|c|c|}
\hline Источник энергии & 2008 г. & 2015 г. & 2020 г. & 2025 г. & 2030 г. & 2035 г. & $\begin{array}{c}\text { Среднего- } \\
\text { довое про- } \\
\text { центное } \\
\text { изменение, } \\
\text { 2008-2035 гг. }\end{array}$ \\
\hline \multicolumn{8}{|c|}{ Страны, входящие в ОЭСР } \\
\hline $\begin{array}{l}\text { Нефть и другие } \\
\text { жидкости }\end{array}$ & 28,1 & 26,2 & 27,0 & 27,4 & 27,6 & 28,0 & 0,0 \\
\hline Природный газ & 19,2 & 20,2 & 21,2 & 21,9 & 22,9 & 24,0 & 0,9 \\
\hline Уголь & 9,2 & 8,6 & 8,6 & 8,8 & 9,0 & 9,2 & 0,0 \\
\hline Электричество & 11,4 & 11,5 & 12,3 & 13,0 & 13,7 & 14,4 & 0,9 \\
\hline ВИЭ & 5,3 & 5,4 & 6,1 & 7,0 & 7,6 & 8,0 & 1,5 \\
\hline Всего ОЭСР & 73,0 & 72,0 & 75,2 & 78,1 & 80,7 & 83,6 & 0,5 \\
\hline \multicolumn{8}{|c|}{ Страны, не входящие в ОЭСР } \\
\hline $\begin{array}{l}\text { Нефть и другие } \\
\text { жидкости }\end{array}$ & 27,2 & 31,2 & 32,2 & 34,4 & 37,5 & 40,6 & 1,5 \\
\hline Природный газ & 25,0 & 29,4 & 33,1 & 36,9 & 41,1 & 45,6 & 2,2 \\
\hline Уголь & 40,7 & 52,7 & 56,0 & 59,9 & 63,3 & 66,2 & 1,8 \\
\hline Электричество & 16,5 & 20,9 & 24,0 & 28,1 & 32,5 & 37,0 & 3,0 \\
\hline ВИЭ & 8,9 & 10,0 & 11,2 & 12,4 & 13,8 & 15,2 & 2,0 \\
\hline $\begin{array}{l}\text { Всего не входящих } \\
\text { в ОЭСР }\end{array}$ & 118,3 & 144,2 & 156,3 & 171,8 & 188,1 & 204,5 & 2,0 \\
\hline \multicolumn{8}{|c|}{ Общемировая тенденция } \\
\hline $\begin{array}{l}\text { Нефть и другие } \\
\text { жидкости }\end{array}$ & 55,3 & 57,5 & 59,2 & 61,9 & 65,1 & 68,6 & 0,8 \\
\hline Природный газ & 44,0 & 49,7 & 54,3 & 58,8 & 63,9 & 69,5 & 1,7 \\
\hline Уголь & 49,8 & 61,2 & 64,5 & 68,7 & 72,3 & 75,5 & 1,5 \\
\hline Электричество & 27,9 & 32,4 & 36,3 & 41,1 & 46,1 & 51,4 & 2,3 \\
\hline ВИЭ & 14,2 & 15,4 & 17,2 & 19,4 & 21,4 & 23,2 & 1,8 \\
\hline Всего & 191,3 & 216,2 & 231,5 & 249,9 & 268,8 & 288,2 & 1,5 \\
\hline
\end{tabular}


нове представлений, описанных в известных исследованиях [11].

Применение программно-целевого метода для управления процессом энергосбережения будет сочетать в себе элементы всех четырех групп методов, представленных выше. Во-первых, данный метод применительно к промышленным предприятиям требует проведения ряда экономических, организационных, технико-технологических и других мер. Во-вторых, разработка целевых программ по энергосбережению, на наш взгляд, подразумевает применение программно-целевого метода. Причем применение данного метода должно осуществляться на начальных этапах формирования программы энергосбережения. Именно на начальных этапах проводятся прогнозные оценки комплекса энергосберегающих мероприятий.

Программно-целевое планирование при подготовке программы энергосбережения включает следующие основные стадии:

1) Формирование прогнозов энергосбережения (на предприятии, в данной отрасли, регионе) и определении генеральной цели программы;

2) Разработка дерева целей программы энергосбережения:

2.1) определение подцелей программы;

2.2) присвоение ранга каждой подцели с учетом ее важности;

3) Определение всех необходимых ресурсов для реализации программы энергосбережения;

4) Разработка программы энергосбережения, сценариев ее осуществления, выбор лучшего из них и детальная его проработка.

В этой работе мы подробно рассмотрим первый этап.

Разработка программы требует четкого задания. На основании задач разработки программы энергосбережения и прогноза этого процесса энергосбережения определяется генеральная цель программы. Разработка генеральной цели программы энергосбережения может осуществляться как минимум двумя методами. Первый метод - дескриптивный, связан с проведением ретроспективного и перспективного анализа исходных данных. Целью ретроспективного анализа является рассмотрение использования энергетических ресурсов с позиции выявления тенденций энергосбережения. Перспективный анализ имеет цели определения периода планирования энергосбережения и нахождения закономерностей энергосбережения, полученных в результате ретроспективного анализа. При этом закономерности выявляются методом экстраполяции [12]. Таким образом получают генеральную цель программы энергосбережения, оценив уменьшение потребления энергетических ресурсов в результате реализации комплекса энергосберегающих мероприятий. Затем полученную тенденцию уменьшения расхода энергетических ресурсов приравнивают к периоду планирования энергосбережения. При этом учитывают предшествующие тенденции энергосбережения. Результат - снижение удельного расхода энергетических ресурсов к выбранному сроку. Этот результат становится генеральной целью программы. Целевые программы носят стратегический характер и разрабатываются на долгосрочную перспективу. В России такие программы разрабатываются на 5-7 лет.

Такая модель предполагает, что каждое $j$-тое мероприятие приносит эффект, характеризующийся абсолютной величиной:

$$
\Delta E_{j}=\left|E_{j}-E_{j-1}\right|,
$$

где $E_{j-1}$ - удельный расход энергии до осуществления энергосберегающего мероприятия; $E_{j}-$ удельный расход энергии после осуществления энергосберегающего мероприятия, где $j=1 \ldots m$.

Общая тенденция снижения потребления энергоресурсов определяется в результате экстраполяции. Основным недостатком такого способа является невозможность определить цель разработки программы энергосбережения, которая позволила бы впоследствии оптимизировать реализацию программы.

Однако задача снижения удельного расхода энергии должна быть связана с осуществлением целевых прогнозов энергосбережения во времени. Таким образом, требуется применять не рассмотренный дескриптивный, а программно-целевой подход к прогнозированию энергосбережения, разработке и реализации энергосберегающих программ.

Мы предлагаем строить целевой прогноз на основании сравнения существующего уровня удельного расхода энергии с уровнем, который необходимо достигнуть. В таком 
случае прогнозируемое снижение удельного расхода энергетических ресурсов должно определяться так:

$$
\Delta E=E_{0}-E_{m},
$$

где $E_{0}-$ существующий удельный расход энергии; $E_{m}-$ требуемый (принимаемый в качестве ориентира программы) уровень удельного расхода энергии.

Следует отметить, что при использовании данного подхода необходимо ориентироваться на сохранение существующего уровня затрат на энергоресурсы, а в идеале - на его снижение. В России промышленность характеризуется постоянным возрастанием потребления энергии, связанной с моральным и физическим износом основных средств. В результате наблюдаем рост затрат на энергетические ресурсы при неизменных или снижающихся объемах производства и реализации промышленной продукции.

\section{Литература}

1. Стандарт ИСО 50001:2011 «Системы энергетического менеджмента. Требования и руководство по применению» (ISO 50001:2011 «Energy management systems — Requirements with guidance for use»).

2. Багиев Г. Л., Златопольский А. Н. Организация, планирование и управление промышленной энергетикой: Учеб. для вузов. М.: Энергоатомиздат, 1993. - 239 с.

3. Безруких П. П., Пашков Е. В., Церерин Ю. А., Плущеевский М. Б. Стандартизация энергопотребления - основа энергосбережения. // Стандарты и качество. - 2000. №11. - C. 19-25.

4. Буравлев А. Т., Гуров П. А. Региональная программа «Качество и ресурсосбереже- ние». // Стандарты и качество. - 2005. №3. - С. 17-20.

5. Кожевников К. Г., Вакулко А. Г. Энергоаудит и нормирование расходов энергоресурсов. - М.: Наука, 2001. - 224 с.

6. Проскуряков В. М., Самуйлявичус Р. И. Эффективность использования топливно-энергетических ресурсов: Показатели, факторы роста, анализ. - М.: Экономика, 2000. - $210 \mathrm{c}$.

7. Туманов C. A. Программно-целевой метод: задачи и перспективы. - М.: Диалог, 1994. - $284 \mathrm{c}$.

8. U.S. Energy Information Administration [Электронный ресурс] / Official webpage. Режим доступа: http://www.eia.gov/forecasts/ ieo/industrial.cfm, свободный. - Загл. с экрана.

9. Energy Efficiency. Renewable Energy [Электронный ресурс] / Official webpage. Режим доступа: http://www1.eere.energy.gov/ industry/ about/pdfs/itp_program_fact_sheet. pdf, свободный. - Загл. с экрана.

10. Environment Canada [Электронный pecypc] / Official webpage. - Режим доступа: http://www.ec.gc.ca/doc/virage-corner/2008-03/ pdf/COM-541_Framework.pdf, свободный. Загл. с экрана.

11. Колбачев Е. Б. Социальная эффективность экономических проектов модернизации и технологического развития. // Вестник Южно-Российского гос. техн. ун-та (НПИ). Серия: Социально-экономические науки. 2008. - №2. - C. 8-17.

12. The Economist [Электронный pecypc] / Official webpage. - Режим доступа: http:// www.economist.com, свободный. - Загл. с экрана. 


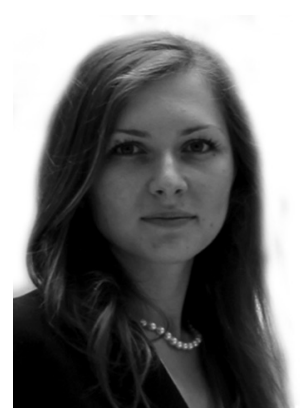

Ольга Николаевна Лагутина - заместитель начальника экономического отдела ЗАО «Ростовгазоаппарат», магистрант Высшей школы управления ЮРГТУ (НПИ).

Olga Nikolayevna Lagutina - deputy chief at the «Rostovgazoapparat» close corporation's economy department, postgraduate of the SRSTU (NPI) Higher School of Management.

344019, Ростов-на-Дону, ул. 19-линия, д. 29

2919 Liniya st., 344019, Rostov-na-Donu, Russia

Тел.: 7 (903) 485-02-65; e-mail: perebeinos90@mail.ru. 